This is a preprint of a paper published in L. N. Oaklander, ed., Debates in the Metaphysics of Time, Bloomsbury, London, 2014, pp. 5170. It is not the final version and cannot be cited. It is posted with permission from the publisher granted on January 16, 2019. The final version is available at www.bloomsbury.com.

\title{
Two metaphysical perspectives on the duration of the present
}

\author{
Francesco Orilia
}

University of Macerata

\section{Introduction}

In his intriguing book Time and Realism (2007), Dolev criticizes some A- and B-theories discussed in current analytic metaphysics of time and proposes his own stance on temporal matters, whose basic tenets we also find in his rejoinder (2014)to Oaklander (2014) in this volume. ${ }^{1}$ This stance benefits in Dolev's opinion from giving up the 'ontological assumption' that undermines the analytic debate and thus Dolev thinks that he is engaged in phenomenology rather than ontology. To be sure, he urges us to pay more attention than it has hitherto been done to data and approaches provided by so-called phenomenologists such as Husserl, Heidegger and Levinas (p. 213), but nevertheless there are good reasons to consider Dolev's positive view as an ontological or metaphysical theory of the kind one already finds in the analytic marketplace (for present purposes, we need not distinguish between ontology and metaphysics). In order to substantiate this claim, I shall show how ontological commitments of the eternalist variety can be extracted from Dolev's anti-Augustinian account of the duration of the present. Dolev's insistence on phenomenological data is commendable, but among such data we find our deep-seated feelings that the past is gone and the future is open, which are in tension with eternalism. Presentism is best fit to accommodate such feelings and Dolev's views on the present can be resisted in favor of the Augustinian line that sees it as durationless, thereby avoiding eternalism and making room for presentism. Yet, a durationless present has a number of problems in store for presentism, at least as traditionally understood. I shall thus end up proposing a moderate presentism, which makes some concession to eternalism and yet preserves the gone past and the open future. 


\section{Some terminological clarifications}

Dolev claims (p. 3) that his work points to 'resolutions for some of the central issues that traditionally make up the metaphysics of time', however

not by offering a metaphysical theory in which answers are given and explanations expounded, but rather, in the tradition of philosophers such as James and Wittgenstein, by working through these issues to the point at which the intelligibility of the theories generated in response to them begins to falter.

The theories in question are identified by Dolev as the tensed or presentist and the tenseless or eternalist views (p. viii and note 2 therein). Dolev has in mind a big subdivision into two broad perspectives, which are often labeled as 'the A-theory' and 'the B-theory', roughly because in the former the so-called A-properties, past, present and future, have an essential and irreducible role, whereas in the latter B-relations, such as earlier and simultaneous, come to the fore. To use the adjectives 'tensed' and 'tenseless' to qualify the A-theory and the B-theory, respectively, is also appropriate, because, roughly, in the former, but not in the latter, tenses are accorded a crucial irreducible role in our effort to express what time is all about. The labels 'presentist' and 'eternalist', as used by Dolev, may however be misleading, for, according to a widespread use that they have, (i) there can be an eternalist of the Atheoretical variety, and (ii) 'presentism' may refer to a doctrine that not all A-theorists endorse (Zimmerman, 2005).

In the use of 'eternalism' that I have in mind, this word refers to a position according to which the ontological inventory, all that there is or exists, includes past and future events or states of affairs ${ }^{2}$ just as it includes the present ones; it includes, for example, the present event of my writing these 
words, the birth of Napoleon and (let us suppose) the birth of the first child of $2020 .^{3}$ The B-theorist can hardly avoid being an eternalist in this sense, for in her view the presentness of an event is a merely perspectival matter, pretty much like the being here of a place in my vicinity. An event is present in this weak sense, present $t_{\mathrm{w}}$, we may say, only in that it is simultaneous with some other event such as the tokening by a subject of certain words (e.g., 'now' or a verb in the present tense) or the subject's having certain thoughts or sensations. And, similarly, other events are past or future in an analogously weak sense, inasmuch as they are earlier or later than present ${ }_{\mathrm{w}}$ events. In this perspective, the pastness $\mathrm{w}_{\mathrm{w}}$ or futurity $_{w}$ of an event does not cancel the event from the ontological inventory, just as New York is not canceled from it, because of the mere fact that I cannot classify it as 'here', while I am in Italy. In sum, we may say, to be a B-theorist amounts to being a $\underline{B-e t e r n a l i s t}$, and vice versa. Dolev considers in detail two representatives of this view, Mellor $(1991,1998)$, and Parfit (on the basis on an unpublished draft). ${ }^{4}$

An A-theorist, on the other hand, may or may not be an eternalist. According to the A-theorist, the presentness of an event is an objective matter. That an event is present in this strong sense, present $_{s}$, we may say, has nothing to do with its simultaneity with other (mental) events. Had not there been any thinking subjects, the events that I am observing right now, the leaves' moving, the sun's shining and so on and so forth would have still been present. An A-theorist is also an eternalist, if she insists that (i) when an event ceases to be present, it does not go out of the ontological inventory, but merely changes from being present to being past and (ii) when an event happens to be present, it has not simply popped into existence, but has merely changed from being future to being present. Dolev discusses a view of this kind, a 'moving now theory', in the version defended by Schlesinger (1980, $1982,1991) .^{5}$

The A-theorist who is an eternalist, the A-eternalist, we may say, will typically add that present events are somehow privileged, that in some sense they are more important, perhaps even more real than past or future ones. For this reason the A-theorist may be called a presentist. ${ }^{6}$ Dolev, I think, is using the label 'presentism' in this sense (p. 5) and thus classifies Schlesinger as a presentist. But it is much more common nowadays to use this label in another way, according to which a presentist is a 
non-eternalist A-theorist who claims that only what is present exists and thus that no past or future events are to be found in the ontological inventory. ${ }^{7}$ Dolev calls this view (or at least something in its vicinity) 'solipsism of the present moment' and discusses it (in $\ 3.2$ ) not by focusing on its typical representatives (such as Prior and, more recently, e.g., P. Ludlow and C. Bourne), but rather on the Dummett of 'The Reality of The Past' (see Dummett, 1978, Ch. 21). To avoid confusions, I keep in line with the dominant terminological trend and disallow the term 'presentism' for moving now A-eternalist views such as Schlesinger's. I thus reserve it for a standpoint according to which only present events exist. My usage is a bit more liberal than the usual one, according to which this term refers, we may say, to typical or traditional presentism, i.e., the view claiming that everything, not just every event, is present. If this is accepted, my moderate presentism counts as presentism (otherwise my use of 'moderate' should be taken like 'fake' in 'fake diamond'). ${ }^{8}$

\section{Ontology and the 'ontological assumption'}

As noted above, according to Dolev, the very intelligibility of the A- and B-theories of time is questionable. This is because they suffer from inner tensions that ultimately depend on an 'ontological assumption', which they both share. Here is his explanation of what this assumption amounts to (pp. 89):

there is an ontology here waiting to be fleshed out, or, what amounts to the same, the idea that reality claims - claims to the effect that events and objects are or are not 'real'-are the key to the philosophical understanding of time. I will call this idea the ontological assumption. ... the shared assumption is that if there are real differences between the past, present, and future then they are ontological differences. 
Thus, the ontological assumption is the claim that events and objects, depending on whether they are past, present or future, may or may not be 'real', so that the key problem in the philosophy of time is deciding whether past, present and future objects and events differ in terms of reality: (i) they are equally real (B-eternalism), (ii) they are all real although perhaps in different ways or degrees (Aeternalism), and (iii) the present is real and the past and future are unreal (presentism). ${ }^{9}$

According to Dolev, the ontological assumption traps the supporters of all these approaches in an 'ontological debate', which must be somehow transcended, by abandoning the assumption, in order to make real progress in our understanding of time. This leads to a 'post-ontological' or 'phenomenological' view bereft of the ontological assumption. Such a view is, according to Dolev, neither an A- nor a B-theory, and captures, as we may say in Sellars' terminology, both our manifest and scientific (relativistic) images regarding time much more closely than A- or B-theoretical approaches can ever aspire to do. Such approaches should be viewed merely as stages or phases (Dolev, 2009, p. 2; in Hegelian fashion, I would add) wherein no truth in the full sense of the term can emerge, for the theses of one stage are contradicted by those of the other, in such a way that one feels trapped in inconsistency. These stages are however necessary in order to reach a superior enlightened phase that supersedes them and in which real truth emerges. Thus, according to Dolev, we must go through the ontological debate in which the supporters of the A- and B- theories are involved in order to have access to the more satisfactory post-ontological phase..$^{10} \mathrm{I}$ shall argue below that Dolev does not ever get to a post-ontological phase, as he proposes his own ontological theory. But before moving to this, let me briefly explain why I am not convinced by how Dolev reviews the debate in order to justify the need to turn to an allegedly post-ontological phase.

Dolev criticizes both A- and B-theories in a general way ( $(4.2)$, because of the fact that they share the ontological assumption. But basically he objects to insisting on a word, 'real', that allows for different and contrasting meanings and is often employed in ordinary language in a way not altogether in line with typical philosophical usages. However, as we shall see below, this problem is easily circumvented, once we clearly focus on the main task of ontology. Moreover, when Dolev turns his 
attention to specific A- or B-theories, (i) it is not clear that his criticism of them really depends on attributing to them the ontological assumption, and (ii) the selection of theories from the debate is too incomplete and idiosyncratic to license any conclusion about a need to dismiss all sorts of A- and Btheories (Meyer, 2009; Tallant, 2009). In particular, Dolev's criticism of B-eternalism focuses on the new B-theory, ${ }^{11}$ according to which, roughly, reality is tenseless, although language and thought are tensed, and tries to capitalize on the inner tension that this duality generates in a view of this sort. However, the B-theorist, despite what is typically assumed nowadays, may well dwell on the old Btheory, according to which both reality and thought and language are tenseless (Orilia and Oaklander, forthcoming). Thus, even if the tension that Dolev tries to bring to the surface could not really be resolved (but see Oaklander, 2014), the B-theorist can eschew it at the outset. ${ }^{12}$ Moreover, Dolev criticism of the A-theory focuses only on Schlesinger's A-eternalism and Dummett's presentism. The former assumes possible worlds (differing from each other as regards which moment in them is present) in accounting for the 'moving now' in a way that most A-theorists would find questionable and unnecessary, while the latter is a highly heterodox version of presentism. Whereas the typical presentist tries to respond to the truthmaker objection to presentism by positing entities that can work as truthmakers of our intuitively true assertions about the past (Magalhães et al., 2010, Part IV, Sect. 3), Dummett argues that many such assertions may well be neither true nor false. Thus, I do not think that, through criticisms of these specific theories, Dolev can show that the debate must be superseded in order to reach a post-ontological view that is neither A nor B.

But is it desirable or even feasible that we reach a post-ontological view, a view about time that is not ontological? I do not think so. The key issue in ontology is, as Quine teaches us, what there is, or, equivalently, what exists or has existence. ${ }^{13}$ In addition, one may also inquire on the issue of whether what exists, or some of what exists, is mind-dependent or objective (mind-independent). In the ontological investigation of time both issues have center stage. As we have seen, the presentist argues

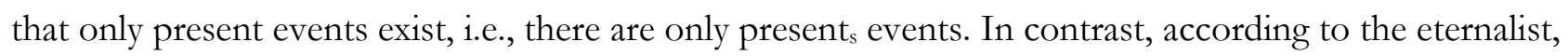
there are also past and future events. And, within the eternalist camp, there is disagreement over 
whether events are (mind-dependently) past $\mathrm{w}_{\mathrm{w}}$, present $_{\mathrm{w}}$ or future $\mathrm{w}_{\mathrm{w}}$, as the B-eternalist has it, or (objectively) past s, $_{\text {, }}$ present $_{\mathrm{s}}$ or future, , as the A-eternalist claims. The word 'real' can cause misunderstandings, because it is used in relation to both types of inquiries, since, in philosophical usage, 'is real' can simply mean 'is' or 'exists', but it can also mean 'is mind-independent'. But, once equivocations due to this double use are set aside, the issues are sufficiently clear. Hence, in the following I shall avoid the use of 'real' as equivalent to 'mind-independent'. With this proviso, I shall go on to argue that Dolev has a definite ontological position in that he is committed to the existence of past, present and future events. Whether he is an A- or a B-eternalist is, as we shall see, less clear. ${ }^{14}$ But, in any case, according to his world view, there are events that the presentist would not acknowledge in her ontological inventory.

4. Dolev's 'post-ontological' perspective on the duration of the present

It may be wrong to deduce Dolev's positive view of time from his critique of the A- and Btheories, since, as we have seen, he regards them as stages that must be superseded, but I suppose it can be legitimately done on the basis of what he says from the allegedly post-ontological perspective of his Ch. 5. And therein Dolev commits himself to an ontological standpoint, namely eternalism. I shall now discuss Dolev's account of the duration of the present in $\ 5.1$ to support this claim (some reference to the subsequent $\int 5.2$, dealing with 'the presence of experience' will also be relevant).

Dolev takes his clue from a reconstruction due to Gale (1968, p. 4) of the famous Augustine's argument about the duration of the present (Confessions, Book XI, Sect. 15). This is usually taken to address the issue of the length of the present, understood as a moment of time, with the conclusion that it is a durationless (pointlike) instant (see, e.g., Dainton, 2000, p. 120): a year cannot be present as a whole, because, if we are, let us suppose, in May, it is at best this month which is present, since the period January-April precedes it and is thus past rather than present, whereas the June-December 
period follows it and is therefore future and not past; similarly, for the month, the week, the day, and so on, until one reaches the durationless instant and can no longer apply this line of reasoning. In contrast, Dolev extracts from Gale's reconstruction of it a 'retrenchability argument' (following Westphal, 2002) that is meant to show that the length of the present, whether understood as a time (occupied by certain events) or as an event or sum of events (occupying a time), is a contextual matter. This is possible, claims Dolev, after having removed 'several hidden assumptions underlying it, which belong to the ontological framework' (p. 120). In particular, Dolev has in mind the presupposition that the present is ontologically privileged in that only the present exists, since 'the past now is not' and 'the future is not yet'. Once this is given up, argues Dolev, the only reason why it may not be appropriate to call a year (and the events within it) present is that the context makes it more apt to focus, say, on a monthly period; similarly for the month, the week, and so on. In other words, whether a certain time or event is present or not is a merely contextual matter. Let us consider more details of the picture that Dolev proposes and then contemplate the ontology that emerges from it.

A crucial notion of this picture is cotemporality, which unfortunately is never explicitly defined. One might surmise that 'cotemporal' is used as synonymous with 'simultaneous', ${ }^{15}$ but it is not so, because the latter is used for events that occur at the same time and thus presumably have the same duration, whereas the former may apply to events of different durations: 'Events or states of affairs can be cotemporal without being equal in duration' (pp. 141-142). From the examples offered by Dolev, we can, I think, infer that he takes two events to be cotemporal if one of them occupies a time interval included in or coinciding with the time interval occupied by the other. Thus, a dog's barking may be cotemporal with a broadcasting of news on TV, because the time occupied by the latter includes the time occupied by the former. But the dog's barking can also be simultaneous with a bell's ringing, because they occupy the same time interval. As we shall now see, Dolev appeals to cotemporality, as so understood, in order to clarify what presentness, in his opinion, amounts to.

Events are said to be present in relation to our 'first-hand experiences' (or immediate experiences, as I'd rather say), which work as standards in assigning A-properties to time and events, 
pretty much as the standard meter in assigning a length to other objects. ${ }^{16}$ Thus, by focusing on a

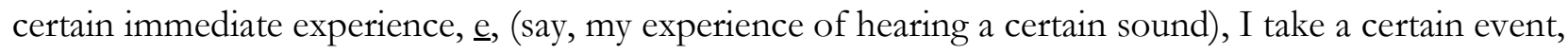
e.g. the bell's ringing, as present, because it is cotemporal with $\underline{\text { e }}$ (pp. 140-141). Or I take the long and complex event consisting of the current Olympic games as present by taking it to be cotemporal with my experience $\underline{e}^{\prime}$ of watching on TV, for instance, a certain soccer match in the Olympic program. Similarly, I can take another event, e.g., the battle of Waterloo, to be past, because it ended before $\underline{e}$ or e'. Derivatively, presentness and other A-properties can be assigned to times, to the extent that they contain events with such A-properties (pp. 124-125).

But these A-properties do not accrue to events and their times intrinsically, but in relation to a context determined by goals and interests (pp. 122-123). Thus, given a certain context, one can take as present either an entire soccer match or the second half of the match (and, derivatively, the times of their occurrences). But no such choice is inherently privileged. Given the appropriate context, claims Dolev, a present event can be of whatever duration (and, derivatively, a present time can be of whatever length). For example, a 9 years long event such the current Mars probing or even some gigantic cosmic event taking millions of years can be taken to be present (cotemporal with some experience working as standard). One could think that, of the immediate experiences, one may say that they are present tout court, independently of any context. But Dolev argues (p. 139) that even for them we need a context, just as we need an appropriate context to say that the standard meter is one meter long (and this context makes sense only because the meter in Paris has already been established as unit of measure).

From this perspective, the Augustinian argument simply shows that, by repeatedly asking appropriate questions, one can keep changing the context in such a way that, from the standpoint of the newly chosen context, the interval that counts as present is smaller than the one that counted as present in the previously chosen context, until one finally gets a context according to which the time is simply a durationless instant. But since no context is privileged or 'more real' than any other, the argument at most shows that, from the point of view of a certain context, the present is pointlike, not 
that it is pointlike in an absolute sense. In essence, Dolev is taking very seriously the well-known fact that in ordinary life we use 'present' and, similarly, 'now', in relations to events or times of different lengths.

By taking ordinary life so seriously, Dolev thinks that he is 'transcending ontology', so as to offer a 'post-ontological' (phenomenological) perspective on time, which is meant to be radically different from the one emerging from the A- and B-theories. But I think that it is not the case that Dolev is really presenting an alternative, or at least not a coherent one; since, in taking so seriously this use of 'present' and 'now', Dolev is re-proposing eternalism, although he seems willing to place it neither in the A-, nor in the B-theoretical camp (wherefrom the suspicion that his proposal is not in the end fully coherent).

Let us see first why Dolev counts as an eternalist (whether of the A- or B-variety). As we saw, the basic point in attributing to someone an ontological position such as eternalism, is to look at her ontological commitments. And Dolev's account of the duration of the present clearly shows that he is committed to the thesis that there are the events typically acknowledged by the eternalist and rejected by the presentist. For example, suppose that I am now watching a live broadcast of a certain soccer match that is part of the Olympic Games and is taking place, let us suppose, a week after the inauguration of the Games. Then, there is, according to Dolev, an event such as the one consisting of the whole occurrence of the Olympic games (it can even count as present, given the appropriate context). But this event is made up of course of many other events, for example, let us suppose, the event, $\underline{\mathrm{e}}_{1}$, consisting of athlete $\underline{\mathrm{A}}$ 's winning the first race of the Games in their first day and the event, $\underline{\mathrm{e}_{\mathrm{n}}}$, consisting of athlete $\underline{\mathrm{Z}}$ 's winning the last race of the Games in their last day. Clearly, Dolev is committed to there being such events. Indeed, as is evident also from Dolev's most recent reflection on a comparable example (2014, p. 18), in his view they may even all count as present, given the appropriate context. ${ }^{17}$ Nevertheless, since $\underline{\mathrm{e}}_{1}$ occurs before my watching the soccer match and $\underline{\mathrm{e}}_{\mathrm{n}}$ occurs after it, they can hardly be present, at least from the point of view of a presentist, who will classify them as past and future, respectively, and will not acknowledge that there really are such things. She will 
admit at most that there are descriptions such as 'the victory of athlete $\underline{A}$ ' or true propositions such as that athlete $\underline{\mathrm{A}}$ won (it remains to be seen what these descriptions refer to and what makes such propositions true, according to the presentist). Not so, however, from the eternalist's point of view and similarly not so from Dolev's point of view. Since these examples could be multiplied ad infinitum, clearly Dolev is committed to precisely the same events as an eternalist and thus it is fair to classify him as such. ${ }^{18}$

Depending on whether, according to Dolev, the pastness or futurity of events such as the victory of athlete $\underline{A}$ and the victory of athlete $\underline{Z}$ are merely pastness ${ }_{w}$ and futurity ${ }_{w}$ or (also) pastness $s_{s}$ and futuritys, Dolev's eternalism is either a B- or an A-eternalism. There are reasons, as we shall now see, in favor of both options.

In favor of an attribution of A-eternalism, one could note that Dolev explicitly insists (p. 128) that his contextualist approach to the present does not make the present mind-dependent and that an event happening now, such as the merging of two clouds, would be present even if there were no experiences working as standards, just as Mount Everest would still be 8,847 meters high even if nobody had selected the Paris rod as standard (p. 143). Moreover, one could remark that his criticism of Schlesinger's A-eternalism in $\ 4.6$ could be easily dispelled. The problem individuated by Dolev is that this position is self-contradictory, because, on the one hand it claims that only the present is real, but, on the other hand, it also takes past and future events as real in that (i) they can work, as I would put it, as truthmakers of sentences about the past or future ${ }^{19}$ and (ii) as the moving now proceeds, unreal future events become real (p. 109). The problem is not serious however. We can for example distinguish degrees of reality or different senses of the word 'real'.

On the other hand, in favor of an attribution of B-eternalism, one could insist that the reason offered by Dolev for the compatibility of his contextualism and the objectivity of the present is not convincing. Dolev's point is that, once a context is set, so that, for example, the whole soccer match that I am watching (rather than, say, its first half) turns out to be present, its duration, as measured by a non-mental entity such as a clock, is an objective matter (p. 128). But this is in line with what a B- 
theorist would say: what is objective is that the soccer match and, say, the movement of the clock's hands from position $\underline{x}$ to position $\underline{y}$ are simultaneous, which is perfectly compatible with denying that these two events are objectively present, in opposition to the A-theory. Moreover, Dolev's account of relativity theory at p. 201 is definitely B-theoretic: simultaneity and copresentness are frame-dependent and thus not transitive, so that there is not a single present but only presentness in a frame of reference. ${ }^{20}$

My final diagnosis is that Dolev endorses an incoherent mixture of A-theoretical and Btheoretical claims.

5. A presentist's perspective on the duration of the present

Thus, it is not clear whether we should attribute to Dolev an A- or a B-theory and perhaps he would say that this is as it should be, since his post-ontological view supersedes both (see, e.g., p. 13). But whatever we make of this, he is definitely committed to eternalism. Now, given Dolev's just desire to save the phenomenological data about time, this is seriously problematic, since eternalism is in tension with two most important such data, namely our deep-seated feelings that (i) the past is gone, so that whatever agreeable or awful events have turned up they are no longer around with their pleasantness or dreadfulness, and (ii) the future is open, so that, depending on our free choices, agreeable or awful events can be brought about. If eternalism is true, the terrible pain that Arthur suffered from years ago somehow still is, the ontological inventory contains it. In other words, there is the unpleasant event of Arthur's being in pain and thus the world, we may say, is affected by a certain degree of unpleasantness, in spite of the fact that Arthur exclaimed with relief: 'thank goodness, it's over'. In contrast, if presentism is true, Arthur's relief is well justified, for the unpleasant event does no longer exist and the world is, at least to that extent, a better world. Similarly, if eternalism is true, there is, let us suppose, the pleasant event of Roderick's getting an A in his homework due next week. We 
may not know which of the two propositions, that Roderick gets an A and that Roderick does not get an $\mathrm{A}$, is true. But in fact one of them is definitely true, because there is its truthmaker. Given our supposition, it is the proposition that Roderick gets an A that has a truthmaker, namely the event of Roderick's getting an A. If, in a compatibilist fashion, we see free will as merely depending on a causal connection between certain intentions and volitions and certain subsequent events, we can still say that Roderick's success in the homework depends on his free choice of working hard for it, but certainly non-compatibilist accounts of free will, which presuppose that neither of those two propositions already has a truthmaker, are doomed at the outset. Vice versa, if presentism is true, no such truthmakers are around and the way is open for viewing these propositions as somehow undetermined, with elbow room for non-compatibilist accounts of free will and more generally for our feeling that the future is open.

Presentism is thus able to save the gone past and the open future by acknowledging only present events in its ontology. This feature of presentism is in my view especially valuable and most crucial to motivate this view. We saw that Dolev's interpretation of the Augustinian argument and his consequent account of the extension of the present however leads to forestall presentism in favor of eternalism. I shall thus look back at the Augustinian argument to see whether one can support a different, more traditional, account of the Augustinian argument, one that does not lead to eternalism.

The traditional interpretation of the Augustinian argument, which takes it as aiming to establish that, strictly speaking, only a durantionless instant can be present, must certainly be squared with the linguistic fact on which Dolev tries to capitalize, namely that we can use 'present' and 'now' to refer, depending on the context, to temporal intervals of various lengths. We can do this by distinguishing, in Chisholm's well-known terminology, between a 'strict and philosophical' and a 'loose and popular' sense of these words. Just as in a loose sense we can call 'identical' two twins who look alike, although in the strict sense of 'identity' they are not identical, we can similarly call 'present' in a loose sense, say, a minute, although in the strict sense of 'present', it is not present. The Augustinian argument must then be understood as having to do with the attribution of presentness in a strict an philosophical sense. 
But why is the presentness of a durationless instant, as opposed to that of, say, a minute, strict and philosophical? As I see it, the reason is that only in the former case is this presentness compatible with these two intuitive principles (at play in the Augustinian argument):

(P1) Whatever is past or future is not present.

(P2) If something temporally precedes or follows what is present, then it is past in the former case, and future in the latter.

The incompatibility in the latter case emerges, because the attribution of presentness to a minute, effected, say, at its $30^{\text {th }}$ second, seemingly involves the attribution of it to all its parts and thus, e.g., to the part going up to its $29^{\text {th }}$ second, which temporally precedes the $30^{\text {th }}$ second and should then be, by (P2), past, and, by (P1), not present. ${ }^{21}$

In sum, it seems that the principles (P1) and (P2) cannot be retained without also buying the Augustinian argument in its traditional interpretation. On the other hand, they had better be saved, if possible, for they are part of our pre-theoretical data about time and in general it is preferable to have, ceteris paribus, a philosophical theory that preserves the pre-theoretical data. Of course, there is nothing wrong, in the appropriate context, to use 'present' in ordinary life to speak of a minute or an hour, but in the philosophical effort of constructing a theory about time, it is legitimate to propose that, strictly speaking, presentness complies with (P1) and (P2) and thus cannot be attributed to an extended interval.

In sum, the principles (P1) and (P2) support the traditional interpretation of the Augustinian argument and thus defuse Dolev's account of it, which, as we saw, leads to eternalism. However, once we combine them with presentism, some serious problems arise. First of all, (P1) and (P2), given presentism, imply that there are no extended intervals of time. ${ }^{22}$ As repeatedly noted by Augustine, this is very puzzling, for we measure such intervals (Confessions, XI, 16, 21) and, we can add, we also refer to them with dates such as 'the year 2013' or 'February 2013'. Moreover, (P1) and (P2), given 
presentism, imply that there is no instant preceding or following the present one, since an instant simply ceases to exist when it becomes past. But this is also puzzling, because, as also noted by Augustine, the present is a present time, and 'not eternity', insofar as 'it passes into time past' (Confessions, XI, 14). In other words, the present instant is an instant of time, because it becomes past and this becoming past should perhaps be looked at as a sort of transformation, rather than as a failing to exist. And in fact we seem to be able to refer to past instants with dates such as 'June 23, 2013 at 3 o' clock'.

Further, it has been noted that, given presentism, the Augustinian argument seems to imply that experiences are durationless, they can only occupy a durationless instant (Dainton 2000, p. 120; Le Poidevin, 2007, p. 79): Given the Augustinian argument, only a durationless instant is present and, according to presentism, there are only present events. Thus, presumably, all events occupy a durationless instant. But experiences are themselves events and thus they must all be durationless. This, however, is perplexing, for our experiences typically appear to involve a duration, with an earlier and a later part. For example, if we look at a moving billiard ball, we seem to have an experience of movement involving, in one fell swoop, the impression of a ball first in a certain position and after in another position. ${ }^{23}$

Finally, independently of the Augustinian argument, which focuses on intervals and instants rather than events, (P1) and (P2), given presentism, seem to force us to deny that there are dynamic events and to acknowledge only static events (Orilia, 2012a). Following Casati et. al, 2010, the former are those that, intuitively, require an extended interval of time, such as the movement of a ball from one place to another, whereas the latter are those that, intuitively, do not require an interval and, at least in principle, can occur at a instant, e.g., a ball's being precisely at a certain position in space. Dynamic events are problematic, given presentism, (P1) and (P3), because they seem to involve an earlier and a later part. For example, if there is the event of a billiard ball moving from place $\mathrm{p}_{1}$ at time $\underline{t}_{1}$ to place $\mathrm{p}_{\mathrm{n}}$ at time $\underline{t}_{n}$, then presumably there is the earlier static event of the ball's being, say, in the intermediate position $\underline{p}_{3}$ at time $\underline{t}_{3}$, followed by the later static event of the ball's being in a successive position $\underline{\underline{p}}_{4}$ at 
time $\underline{t}_{4}$. But the earlier static event is past and not present in view of (P2) and (P1) (suppose the ball is presently in $\mathrm{p}_{4}$ ) and thus non-existent, if we accept presentism. And, if we accept presentism, the dynamic event as a whole can hardly count as existent, since it would have non-existent parts.

What can we make of all this? I propose to deal with these issues by advancing moderate presentism, which retains the basic intuition of typical presentism, according to which only present events exist, but is prepared to acknowledge past and future durationless instants in addition to the present one and thus, one may say, extended intervals, as somehow made up of such instants. Such moments of time (instants and intervals) should be conceived of in a substantialist, Newtonian, fashion, and not as somehow arising from classes of simultaneous events (Russell, 1914; Whitehead, 1929) or mereological sums thereof (Pianesi et al., 1996), as the opposite relationalist account has it. For otherwise the idea that there are only present events would be immediately given up. If, for example, the instant referred to by '26 October 1860 at 12:30 p.m., Italian time' were nothing over and above a class or mereological sum of events, including, inter alia, the event of Garibaldi and King Vittorio Emanuele II's meeting in Teano, then our ontological inventory should acknowledge this past event. If we want to deny that there are such events and yet admit that there are past (and future) instants, we have to see instants as items over and above the events that occur at them. The idea then is that the present instant is the instant at which, objectively, events occur, the present events (the only ones that there are), whereas the past and future instants are those that precede and follow the present instant, in a temporal order somehow primitively given in such as way as to give a direction to time (as perhaps a substantialist eternalist may have it). Such past and future instants are, we may say, 'empty', since events no longer or not yet occur at them. The becoming present of a future instant is then not its coming to be, but, as hinted above, a sort of 'transformation', from its being empty to its being such that events occur at it. Similarly, the becoming past of a present instant is its becoming empty, after having hosted events. In contrast, events, in keeping with the crucial intuition of presentism, are not subject to a transformation, to becoming present after having been future and past after having been present. They 
are rather subject to absolute becoming, they come into being when a certain property is exemplified by an object or a relation is jointly exemplified by some objects.

Let us now briefly see how we can deal with dynamic events in the light of these additional resources. ${ }^{24}$ Consider again the ball's moving from position $\mathrm{p}_{1}$ to position $\mathrm{p}_{n}$. We can now say that, at any time during this movement, the ball is not only exemplifying 'present-centered' properties such as, say, being in position $\mathrm{p}_{3}$, but also 'past-oriented' ('time-indexed') properties such as having been in position $\underline{\underline{p}}_{2}$ at time $\underline{t}_{2}$ and ('time-indexed') 'future-oriented' ones, whose nature I now turn to explain, by focusing for illustrative purposes on the ball's presently being in position $\underline{p}_{3}$ at time $\underline{t}_{3}$ in the course of its movement.

We can understand future-oriented properties in two ways, depending on whether or not we take it as fully determined at $\underline{t}_{3}$ that the ball would then be in $\underline{\underline{p}}_{4}$ at time $\underline{t}_{4}$. If it is fully determined, then the ball has at time $\underline{\mathrm{t}}_{1}$ the future-oriented property of going to be in $\underline{\underline{p}}_{4}$ at time $\underline{\mathrm{t}}_{4}$. On the other hand, if we do not take it to be fully determined at $\underline{\mathrm{t}}_{3}$ that the ball will be in $\underline{\mathrm{p}}_{4}$ at time $\underline{\mathrm{t}}_{4}$, the future-oriented property that the ball has at $\underline{\mathrm{t}}_{3}$ is a mere propensity, a property such as being potentially in place $\underline{\underline{p}}_{4}$ at time $\underline{t}_{4}$. We can conceive of it as a property that the ball exemplifies insofar as, roughly speaking, it is storing (say, by having been pushed) some kinetic energy leading in a certain direction. Having this property does not necessarily result in its being in $\mathrm{p}_{4}$ at time $\underline{t}_{4}$, for, e.g., there can be an intervening obstacle.

According to this perspective, dynamic events, rather than being discarded, are, we may say, supervenient on static events, involving present-centered and past- and future-oriented properties, all occurring at the present instant. Thus, for example, there is the dynamic event of our moving ball

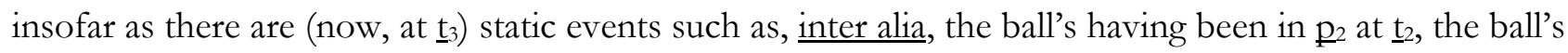
being in $\underline{p}_{3}$, the ball's being potentially in $\underline{\underline{p}}_{4}$ at $\underline{t}_{4}$. Or, if one wishes, a dynamic event is a 'conjunction' of static events of this sort and thus a conjunctive event.

In this way of dealing with dynamic events, moderate presentism should perhaps be prepared to make another concession to eternalism and admit in its ontological inventory past objects; following 
Williamson (2002), they could be viewed as ex-concrete objects, objects that used to be in space and where thus concrete, but are no longer in space. For it seems we can observe dynamic events involving the ceasing to be of objects, their turning to be ex-concrete. For example, our billiard ball could for some reason explode in reaching position $\mathrm{p}_{3}$. Be that as it may, admitting ex-concrete objects allows moderate presentism to deal with the notorious problem of the truthmaking objection to presentism in way that is not open to typical presentism..$^{25}$ For example, suppose it is now true that Arthur, who passed away long ago, suffered from a headache at noon on 4 May 1956. This proposition has a truthmaker, i.e. the event consisting of Arthur's having had a headache at noon on 4 May 1956, since Arthur, albeit ex-concrete, presently exemplifies the past-oriented property of having had a headache at noon on 4 May 1956: after becoming ex-concrete, an object does not lose the past-oriented properties that it has accumulated as time goes by, and, we may add, it can even gain new present-centered intentional properties, such as being observed (think of a star exploded long ago and yet in our firmament) or being admired (think of Arthur Prior). But it cannot have present-centered physical or mental properties such as having a certain mass or a headache.

Let us finally deal with the issue of the apparent duration of experiences. From the perspective of a presentism that takes the present as a durationless instant, we can deal with this, by appealing to Husserl's retentions, impressions and protentions, in contrast with Dolev's (2014, p. 18) misgivings about Husserl's approach, but in line with Dolev's recommendation to pay attention to phenomenologists, which is not at all in contrast with doing ontology. The idea is that an experience, while occupying, as any other event, a durationless instant, may well look extended, because it involves not only impressions, but also retentions and protentions (Dainton, 2010, \6.3). With past-oriented, present-centered and future-oriented properties in out ontology, we can understand retentions, impressions and protentions as mental representations of three kinds of static events: objects' exemplifying past-oriented properties (the ball's having been in $\underline{\underline{p}}_{2}$ at $\underline{t}_{2}$ ), objects' exemplifying presentcentered properties (the ball's being in $\mathrm{p}_{3}$ ) and objects' exemplifying future-oriented properties (the ball's potentially being in $\underline{p}_{4}$ at $\left.\underline{t}_{4}\right)$. 


\section{Conclusion}

Any theory has its own ontological commitments and in theorizing about time there is no exception to this. It is thus impossible to be engaged in 'post-ontology' or mere phenomenology, nor should this worry us, as long as we have the appropriate canons of rigor and avoid equivocations. Thus, Dolev himself has his own ontological, or metaphysical, theory of time, which commits him to eternalism. Eternalism, however, cannot easily accommodate our feelings that the past is gone and the future open. Presentism is best fit for this task and moderate presentism can accomplish it, without the difficulties of typical presentism. ${ }^{26}$

\section{References}

Casati, R. and Varzi, A. (2010), 'Events', in E. N. Zalta (ed), The Stanford Encyclopedia of Philosophy (Spring 2010 edn). URL = <http://plato.stanford.edu/archives/spr2010/entries/events/>.

Castañeda, H.-N. (1980), On Philosophical Method. Bloomington, IN: Noûs Publications.

Dainton, B. (2000), Stream of Consciousness. London: Routledge.

Dainton, B. (2010), 'Temporal Consciousness', in E. N. Zalta (ed), The Stanford Encyclopedia of Philosophy (Spring 2010 edn). URL =

<http://plato.stanford.edu/archives/fall2010/entries/consciousness-temporal/>. 
Dolev, Y. (2007), Time and Realism, Cambridge, Mass.: The MIT Press.

Dolev, Y. (2009), 'Time and Ontology: A Reply to Meyer'. Iyyun. The Jerusalem Philosophical Quarterly, 58, 292-300.

Dolev, Y. (2014), 'Motion and Passage - The Old B-Theory and Phenomenology', in L. N. Oaklander (ed), Debates in the Metaphysics of Time. London: Bloomsbury.

Dummett, M. (1978), Truth and Other Enigmas. Cambridge, Mass.: Harvard University Press.

Gale, R. (ed) (1968), The Philosophy of Time. New Jersey: Humanities Press.

Magalhães E. and Oaklander, N. (eds) (2010), Presentism. Essential Readings, Lanham: Lexington Books.

Mellor, D. H. (1981), Real Time. Cambridge: Cambridge University Press.

Mellor, D. H. (1998), Real Time II. London: Routledge.

Meyer, U. (2009), 'Yuval Dolev, Time and Realism (The MIT Press, 2007)'. Iyyun. The Jerusalem Philosophical Quarterly, 58, 92-101.

Le Poidevin, R. (2007), The Images of Time. Oxford: Oxford University Press.

Oaklander, L. N. (2014), 'Dolev's Anti-Metaphysica Realism: A Critique', in L. N. Oaklander (ed), Debates in the Metaphysics of Time. London: Bloomsbury. 
Orilia, F. (2012a), 'Dynamic Events and Presentism'. Philosophical Studies, 160, 407-414.

Orilia, F. (2012b), Filosofia del tempo. Roma: Carocci.

Orilia, F. (forthcoming). 'This Moment and The next Moment', in V. Fano, F. Orilia and G. Macchia (eds), A Priori and A Posteriori Studies on Space and Time. Berlin: De Gruyter.

Orilia, F. and Oaklander, N. (forthcoming), 'Do We Really Need a New B-theory of Time?'. Topoi.

Pianesi F. and Varzi A. C. (1996), 'Events, Topology, and Temporal Relations'. The Monist, 78, 89-116.

Russell, B. (1914), Our Knowledge of the External World. London: Allen and Unwin.

Schlesinger, G. N. (1980), Aspects of Time. Indianapolis: Hackett.

Schlesinger, G. N. (1982), 'How Time Flies'. Mind, 91: 501-523.

Schlesinger, G. N. (1991). 'E Pur Si Muove'. Philosophical Quarterly, 41: 427-441.

Westphal, J. (2002), 'The Retrenchability of “the Present”". Analysis, 62: 4-10.

Zimmerman, D. (2005), 'The A-Theory of Time, The B-Theory of Time and "Taking Tense Seriously"”, Dialectica, 59, 401-57.

Whitehead, A. N. (1929), Process and Reality. An Essay in Cosmology. New York: Macmillan. 
Williamson, T. (2002), 'Necessary Existents', in A. O'Hear (ed), Logic, Thought and Language, Cambridge: Cambridge University Press, pp. 233-251.

\footnotetext{
${ }^{1}$ Unless otherwise indicated, page and paragraphs references in the following are to Dolev's book and my attributions of views to Dolev are mainly based on it. However, occasional references to Dolev, 2014, and to another work by Dolev (2009) will also be appropriate.
}

${ }^{2}$ I treat 'event' and 'state of affairs' as synonymous (I think this is basically in line with Dolev's usage, at least as regards the issues discussed here).

${ }^{3}$ To call a view of this kind 'eternalist' is not of course meant to imply that such events are eternal in the sense of being everlasting, i.e., existing at all times (see Oaklander, 2014).

${ }^{4}$ The version of the old B-theory discussed by Dolev (2014) in this volume is another representative.

${ }^{5}$ One should not be misled into thinking that A-eternalism is simply B-eternalism with a moving now superadded, so to speak, to a temporal series of times or events resulting from B-relations, in such a way that we could get B-eternalism back, by taking the moving now away. For A-eternalism is in the first place an $\underline{\text { A-theory }}$ and thus considers A-properties essential for there to be time at all. Thus, from the perspective of A-eternalism, since the exemplification of A-properties by times or events is dependent on the moving now, without such moving now there would be no temporal series. To put it otherwise, the B-series would not be a temporal series.

${ }^{6}$ And in fact there are A-theorists, such as W. L. Craig and Q. Smith, who classify themselves as presentists, even though they are best viewed, given my preferred terminology, as A-eternalists (Zimmerman, 2005).

${ }^{7}$ There may be qualms over this way of classifying approaches. For example, Oaklander, in private correspondence, has commented thus on this matter (with reference to the $\mathrm{B} / \mathrm{R}$ theory, discussed in Oaklander, 2014 (basically, a B-theory, as I see it; 'B' and 'R' remind us of Broad and Russell, respectively): 
[this classification] assumes that both 'eternalists' accept the existence of temporal relations and just debate over the ontological status of the present, but that is potentially damning for the B/R theory (since the A-eternalist would deny that without the privileged now we have temporal relations) or damning for the A-theorist eternalist, since temporal relations (of the R-theoretic stripe [B-relations, or at least akin to them]) cannot obtain with terms that have A-properties. Thus, if the temporal relations that R-theorists accept is common to both forms of eternalism, then A-theoretic eternalism must deny temporal relations and so morphs into true presentism.

I think that the B-theorist would insist that a privileged now is not required for the instantiation of temporal B-relations and the eternalist A-theorist would argue that s he can understand temporal relations in way that does not imply presentism. For present purposes, however, I think that we can put these issues aside, since they do not hinge on what I want to focus on here.

${ }^{8}$ It should be noted that the presentist, whether traditional or moderate, does not deny that, e.g., the birth of Napoleon or (perhaps) the birth of the first child of 2021 existed (was in the ontological inventory) or will exist (will be in the ontological inventory). The point of the presentist is that they do not exist now. However, to the extent that she is committed to the truth now of the past tense proposition that Napolen's birth existed and the future tense proposition that the birth of the first child of 2021 will exist, she owes us an account of what makes these propositions true compatible with her view of what the ontological inventory contains now. More on this later.

${ }^{9}$ There is a fourth option seriously considered in the current literature, namely that the past and present are real whereas the future is unreal or branching. But since Dolev does not discuss it, I have neglected it here.

${ }^{10}$ In an ideal reconstruction, I myself would rather distinguish (following Castañeda, 1980) a phase dedicated to the collection of pre-theoretical data, which typically involves puzzles and thus conflicting intuitions ('protophilosophy'), a subsequent phase of theory construction ('symphilosophy') where any 
apparent protophilosophical contradiction is removed, and finally a phase of intertheoretic comparisons ('diaphilosophy').

${ }^{11}$ Mellor, on whom Dolev focuses, is a typical supporter of the new B-theory. The fact that Dolev also discusses Parfit's unpublished version of the B-theory does not alter the basic fact that Dolev's misgivings about the B-theory ultimately derive from his focusing on the new B-theory.

${ }^{12}$ In his rejoinder to Oaklander (2014), Dolev (2014) has now taken up the old B-theory as well, or at least Oaklander's attempt to revive it, and claimed that the ontological assumption afflicts it as well, to the extent that, in Dolev's words, (2014, p. 23), 'it is presented as an ontological theory'. I cannot engage in a full discussion of this here, but it should be evident that my points against Dolev's misgivings regarding the ontological assumptions also apply to his criticism of the old B-theory.

${ }^{13}$ I basically side with Meyer (2009, p. 97), when he urges that in looking at the A vs. B dispute we should not worry about how 'real' is used and should rather concentrate on what exists, according to the parties.

${ }^{14}$ Thus, I do not have Meyer's (2009, n. 7, p. 9) impression that Dolev's sympathies simply lie with the B-theory. Meyer's impression may seem to be confirmed by this explicit claim by Dolev (2014, Conclusion, p. 23): 'The view I have been defending has much in common with the old B-theory (and very little with the new one, or with any versions of the A-theory)'. Yet, as we shall, there are significant A-theoretical elements in Dolev's standpoint.

${ }^{15}$ The occurrence of these terms at p. 92 may suggest this. Dolev also uses another related term, 'copresent', in discussing relativity theory, but seems to take it as equivalent to 'simultaneous' (see p. 201).

${ }^{16}$ The standard meter is one and public, whereas experiences are many and private; thus, Dolev prefers to say that the latter work as 'quasi-standards' (p. 140).

${ }^{17}$ It may be objected that in making such assertions I am attributing to Dolev a view that is not really his, for he has explicitly disavowed 'the phenomenologically and conceptually ungrounded presupposition that events [such as the Olympic Games] consist of parts [such as the victories of 
athlete A and athlete B] that are somehow brought together to form a unity' (Dolev, 2014, p. 19). Yet, Dolev himself speaks of events in part/whole terms: 'some present events [the second part of a symphony, broadcast live on TV] are parts of other present events [the whole symphony, broadcast live on the radio]' (Dolev, 2014, p. 17).

${ }^{18}$ This is confirmed by what Dolev says of past and future objects and events, e.g., in relation to memory at p. 153, to future contingents at pp. 187-204, and to relativity theory at p. 202. And also by what he says of time passage, which is understood as the becoming present and then past of future objects and events, with the proviso that this does not imply their turning from being 'not real' to being 'real' and then to 'not real' again, since the ontological assumption has been given up (pp. 164-165). The fact that there are, in Dolev's opinion, the objects and events subject to this becoming is sufficient to nail him to the eternalist's ontological commitments, in spite of his refusal to use the words 'real' or 'not real' for them.

${ }^{19}$ In Dolev's terminology (p. 109) there are 'conditions obtaining at any time, past, present, or future, as truth conditions, as that the obtaining of which establishes the truth or falsity of sentences'.

${ }^{20}$ This is B-theoretic up to a point, because, given a space-like separation between two events, even Brelations linking such events are frame-relative. But this is a problem (underestimated, in my view) for any approach that wants to reconcile relativity theory with the B-theory and I shall set this issue aside here.

${ }^{21}$ It is not clear to me whether Dolev would agree or disagree with the idea that the attribution of presentness to the minute implies an attribution of presentness to all its parts. In favor of the first hypothesis there is his claim that 'present events have parts that are not themselves present' (Dolev, 2014, p. 16). In favor of the second hypothesis, there is his claim that 'some present events are parts of other present events' (Dolev, 2014, p. 17). Be this as it may, I understand that one could insist that the being present of the minute does not imply that all its parts are also present, but only that a certain instant within it is such. But this is another way of saying that only a durantionless instant is strictly speaking present, which is what I am pressing. 
${ }^{22}$ Since, as we saw, they cannot be present and thus do not exist, according to presentism.

${ }^{23}$ Dolev (2014, pp. 18-19) tries to exploit the durational character of experiences in order to support his conception of time, but he does so by also claiming that experiences, and more generally events, do not have successive parts that somehow form a unity. In contrast, it seems to me that our experiences, e.g., as of a fast moving objects, do appear to have successive (earlier and later) parts. There is no room to try a diagnosis of this disagreement here.

${ }^{24}$ See Orilia, 2012a, and Orilia, forthcoming, for some additional details.

${ }^{25}$ By appealing to ex-concrete objects, moderate presentism can also deal with intertemporal relations such as causation, in a way that is not open to traditional presentism (Orilia, 2012b, $₫$ 6.7). Reasons of space prevent me from going into this here.

${ }^{26}$ I wish to thank L. Nathan Oaklander for his valuable advice and his comments on a previous version of this paper. 